\title{
The Influence of Hygroscopic Movement on Seed Dispersal in Daucus carota (Apiaceae)
}

\author{
Elizabeth P. Lacey* \\ Department of Botany, University of Michigan, Ann Arbor, Michigan 48109, USA
}

\begin{abstract}
Summary. The influence of hygroscopic movement on seed dispersal in Daucus carota was examined. When relative humidity increases, umbels containing mature fruits close; when relative humidity drops, umbels open. Tests of the effectiveness of smalland large-angled umbels on dispersing seeds under various conditions demonstrate that umbels responding greatly to relative humidity (i.e. opening wide) lose seeds more quickly than do umbels responding little, and do not disperse them as far. As relative humidity increases, number of dispersing seeds drops to near zero. Response to changes in relative humidity within an umbel progressively increases from late August when dispersal begins. Umbels that slowly increase their response retain some seeds that may disperse over snow in winter. Individual variation in response to relative humidity is high among plants beginning dispersal at the same time. This variability is probably maintained by the variable consequences of dispersing seeds at different times.
\end{abstract}

\section{Introduction}

Because dispersal is critical to plant survival, studies of dispersal mechanisms abound (Kerner 1895; Guppy 1912; Ridley 1930; van der Pijl 1972; Harper 1977). These investigations take two tacks: some describe dispersal qualitatively, while others quantify the mechanism or its spatial or temporal consequences. Most studies have taken the former approach, and few the latter. Workers concerned with the distance that wind disperses seeds have generated most of the quantitative data (Wolfenbarger 1946; Levin and Kerster 1969; Sheldon and Burrows 1973; Harper 1977), but have drawn only general conclusions about the evolutionary or ecological importance of dispersal mechanisms.

I present here results of a quantitative study of how hygroscopic movement affects seed dispersal in Daucus carota, an early successional weed. Hygroscopic movement, which is caused by absorption and loss of water associated with change in relative humidity, influences dispersal in a number of plants. Sporangia in leptosporangiate ferns, elaters in Equisetum, and involucral bracts of Centaurea all exhibit hygroscopic movement (Haberlandt 1914; Fitting et al. 1921). Bracts in species of Cirsium and Solidago respond similarly (personal observation). In Daucus carota, hygroscopic movement occurs in the umbels of dead plants. Although it is known to influence seed dispersal in general, no one has yet measured its effects on dispersal or even under what conditions it occurs. To do this I have asked four questions: (i) How does

* Present address: Department of Biology, University of North Carolina, Greensboro, N.C. 27412 hygroscopic movement vary with changes in relative humidity? (ii) Does the response to relative humidity change with time? (iii) How variable is hygroscopic movement among individuals? and (iv) In what way does it affect seed dispersal?

\section{Biology of Daucus carota}

Daucus carota L. (Queen Anne's Lace or wild carrot) is a member of the group D. carota ssp. aggregate carota (Small 1978) in the family Apiaceae (Umbelliferae). Introduced from Europe, it is now found throughout northern United States and southern Canada and as far south as the Georgia Piedmont.

Although usually reported to be a biennial, it is sometimes an annual, and sometimes longer-lived but still semelparous. The flowering plant produces many compound umbels (Fig. 1) arranged in several orders according to position on the plant. The terminal umbel is at the tip of the main stem. The first-order laterals are at the tips of branches arising from the main stem. The second order laterals are at the tips of branches arising from these branches, and so on. Because most seeds are produced by the terminal and first-order laterals and because seed release from these umbels reflects that from all orders of umbels (Lacey 1978), I present data only from these.

Although most plants flower from early July through August in southeastern Michigan, occasional plants flower in June or September. Terminal umbels reach anthesis first and the first-order laterals follow two weeks later. The umbels open flat or even

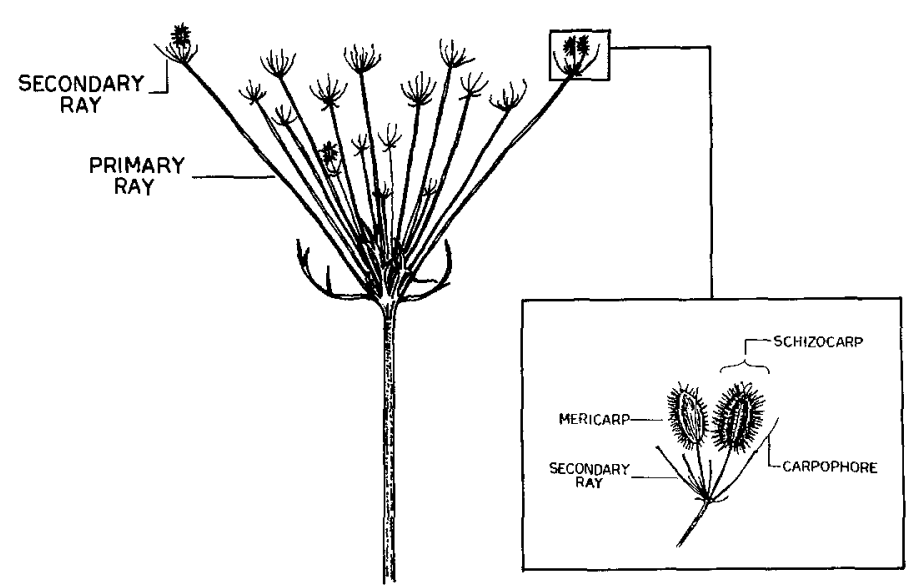

Fig. 1. Compound umbel with four fruits (schizocarps) remaining. A mericarp is one half a schizocarp 
become convex at anthesis, after which they close tightly. The cause of closing is unknown. This position is retained through fruit maturation. Approximately five weeks after flowering, an umbel dries up and seed dispersal begins. The fruit is a schizocarp, which usually splits into two mericarps; these disperse separately (Fig. 1). Because each mericarp contains one seed, I will, for simplicity, refer to seed dispersal rather than to mericarp dispersal.

The dispersal season extends from late August through the following winter. In the next spring one commonly finds in a population several plants still retaining many seeds. Seeds disperse from the edge of the umbel toward the center, and those from one umbel are usually dispersed over several months. Although Salisbury (1961) and Stebbins (1971) have inferred from fruit morphology that the seeds are dispersed by animals, my data show that wind is an important dispersal agent (Lacey 1980).

Hygroscopic movement begins with death of an umbel. The outer primary rays (Fig. 1) respond to changes in relative humidity by bending toward the umbel axis when relative humidity increases and away from the umbel axis when relative humidity decreases. Thellung (1929) first reported this hygroscopic movement, which can be explained by differential microfibril orientation in the inner and outer halves of the outer rays of the umbel (Lacey 1978). While microfibrils have a predominantly transverse orientation in cells in the outer half of the ray, they have a predominantly longitudinal orientation in the inner half.

\section{Methods}

To measure hygroscopic movement, I approximated the umbel angle $(\theta)$ and expressed it in terms of the ratio: largest diameter of the umbel $(D)$ over length of the longest outer ray $(R)$ (Fig. 2$)$. The parameters are related as follows:

$D / R=2 \sin \theta$

Sometimes at low relative humidities the outer rays became reflexed so much that the diameter did not truly represent the amount of opening (Fig. 2B). In these instances, I set $D$ equal to $2 R$ for any umbel in which the outer rays were reflexed below the junction $(\mathrm{J})$ of the primary rays and the main stem of the umbel. The umbel was assumed to have opened to a maximum angle of $180^{\circ}$

To document individual umbel response to changes in relative humidity, I determined $D / R$ ratios for 684 umbels at 6 relative humidities. In spring $1976 \mathrm{I}$ marked rosettes in four fields abandoned for 2,5 , $7-8$, and $>30$ years (Lacey 1978), and in mid-October, I collected plants that had flowered. At this time the umbels on most plants were responding to relative humidity and most plants were intact. I stored all plants in the laboratory until December 1976, when I hung them upside-down in a walk-in growth chamber where relative humidity could be adjusted. Twelve hours after setting the chamber at $33 \%, 66 \%, 77 \%$ and $89 \%$ R.H. respectively, I measured ray length and diameter to the nearest $\mathrm{mm}$. for each intact umbel. I measured relative humidity with a batterypowered psychrometer. I also measured ray length and diameter of the umbels while dry (12-20\% R.H.) and while satura ted ( $\equiv 100 \%$ R.H.) in the laboratory. Temperature ranged from $21-26^{\circ} \mathrm{C}$ for all measurements.

Temporal variation in hygroscopic movement was examined in two ways. First, I compared $D / R$ ratios of terminal umbels of plants that flowered at three different times in the 30 year old field. Only for this field were samples sizes large enough for results to be meaningful. Second, I examined changes in $D / R$ ratios of terminal umbels that I collected at different times throughout the dispersal season. These umbels had all flowered in mid-July when they had been marked for collection at a specified time in the fall or winter. In February 1977 after I had collected all umbels I soaked them in water and air dried them for

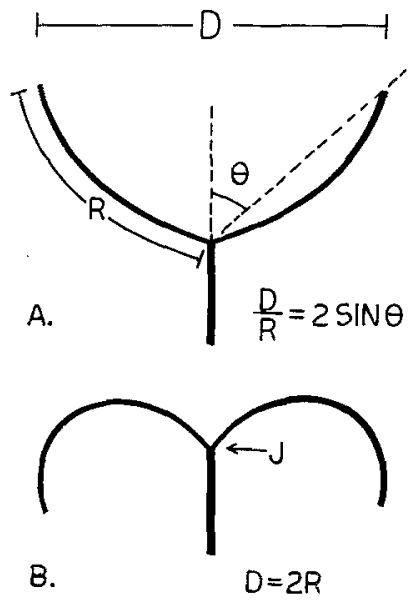

Fig. 2. A Schematic drawing of an umbel of diameter $(D)$, ray length $(R)$ and angle of opening $(\theta)$. B Umbel with same ray length and diameter but with rays reflexed beyond junction $(J)$ of the stem and primary rays

$24 \mathrm{~h}$ at $35-40 \% \mathrm{R} . \mathrm{H}$. I then measured ray length and diameter to the nearest $0.5 \mathrm{~cm}$. From collection time to time of measurement I stored the umbels dry in the laboratory.

I hypothesized that hygroscopic movement influences the rate of seed dispersal. Umbels that open wide at a given relative humidity should lose their seeds more quickly than umbels opening little at the same relative humidity. This hypothesis was tested in two ways. First I compared $D / R$ ratios of terminal umbels retaining many seeds with ratios of umbels containing few seeds in late winter. In March 1978 I collected from one population umbels that either had 1) many seeds left or 2) fewer than 10 seeds left. The umbels were only partially open when $I$ collected them. To sample the empty umbels objectively, I chose arbitrarily, but independently of the carrot plants, a path through the field and collected any empty terminal umbel encountered. Full umbels were not abundant and so were simply collected when seen. Because thomisid and salticid spider webs, which are built when the plant is alive, augment seed retention in an umbel, only umbels showing no signs of webbing were collected. After removing all seeds I soaked the umbels in water and air dried them in the lab $(20 \%$ R.H.) for $24 \mathrm{~h}$. I then measured ray length and diameter to the nearest $0.5 \mathrm{~cm}$.

I also conducted two experiments to determine number and dispersal distance of seeds dispersing from large- and small-angled umbels under controlled conditions. In the first experiment I selected two umbels that differed in degree of opening $(D / R=1.75$ and 1.25$)$ but otherwise were very similar (same longest ray length $=4.0 \mathrm{~cm}$, secondary rays intact, and approximately equal number of primary rays). I removed all seeds from the first umbel and dropped $\sim 300$ seeds into it. The umbel was held in front of a fan with cheesecloth covering the floor in front of the fan. While I held the umbel stem at floor level, the umbel itself was $0.48 \mathrm{~m}$ above the floor. The fan ran for one minute, after which I counted dispersed seeds and measured the smallest distance between each seed and the fan. This procedure was then repeated with the same seeds and the other umbel. There were three replicates for each umbel at each of three wind speeds: fast $=3.1 \mathrm{~m}$ per second (mps), medium $=$ $1.8 \mathrm{mps}$, and slow $=0.9 \mathrm{mps}$. I measured wind speed with an anemometer held $0.48 \mathrm{~m}$ from the floor. To test whether the results obtained from this pair of umbels were peculiar to these umbels, I repeated the experiment at high wind speed using a second pair of umbels.

The second experiment tested the effects of simulated rain on seed loss. The procedure was basically the same as for the fan experiment except that this time each umbel was given one blast of water from a shower. In this experiment $I$ used two large-angled umbels in the dry expanded state $(D / R$ ratios $=1.86$ and 1.75$)$ and in the wet closed state. To close the umbels around the seeds the umbels were gently sprinkled with water after dropping the seeds into them. 


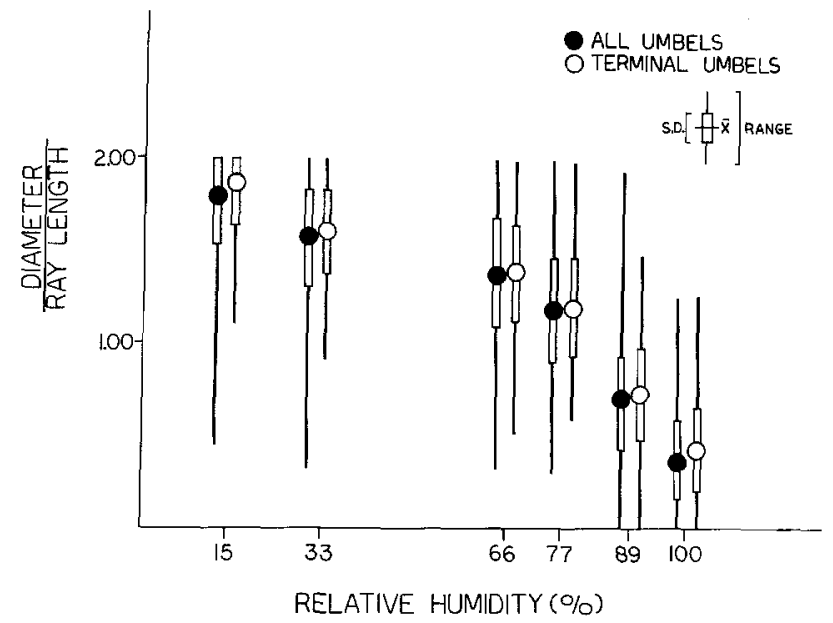

Fig. 3. D/R ratios for 684 umbels at 6 relative humidities

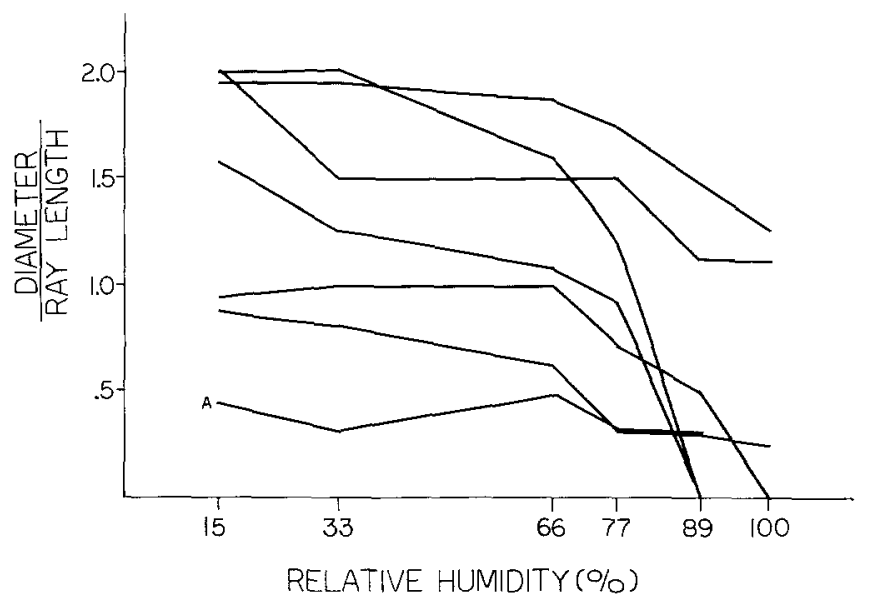

Fig. 4. D/R ratios for 7 umbels at 6 relative humidities. Each line represents a different umbel. The first-order lateral umbels that responded little to relative humidity are represented by " $\mathrm{A}$ "

\section{Results}

Mean $D / R$ ratios decrease monotonically with increasing relativt humidity for all but five of 684 umbels sampled (Fig. 3). The greatest drop is observed at high humidities. Mean $D / R$ ratios for terminal umbels alone represent quite well the mean ratios for all umbels measured. The differences in range of $D / R$ ratios show that laterals, unlike terminals, sometimes respond little to relative humidity. Variation among umbels regardless of position and flowering time is high (Fig. 4).

Mean $D / R$ ratios increase significantly during the fall (Fig. 5; median stat. $=1.56, d f=5, p=0.025) . D / R$ ratios of umbels collected in August and September are not significantly different from each other (median stat. $=1.32, d f=2, p=0.58$ ), nor are the higher $D / R$ ratios of umbels collected from October to January (median stat. $=1.74, d f=2, p=0.49$ ). This same trend is seen in plants that were collected at the same time but flowered at different times (Table 1). Among plants collected at the same time $D / R$ ratios increase with delay in flowering, though the differences are not significant at $p=0.05$. Because of the short time span considered here (flowering time differences range over only 4 weeks), this lack of significance is reasonable.

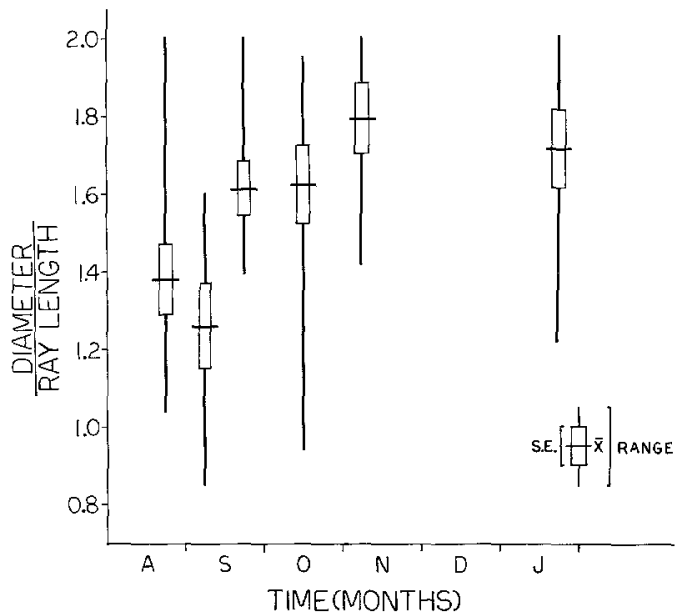

Fig. 5. $D / R$ ratios of umbels that flowered in mid-July and that were collected at different times. Measurements made at $35-40 \%$ RH. $(N=7-$ 10 for each collection time.)

Table 1. D/R ratios for terminal umbels flowering at different times: 30 YR old field 1976

\begin{tabular}{llll}
\hline $\begin{array}{l}\text { Relative humidity } \\
(\%)\end{array}$ & Flowering time & $N$ & $\bar{X} \pm$ S.D. \\
\hline $89^{\text {a }}$ & 19-25 July & 48 & $0.80 \pm 0.21$ \\
& 26 July-5 August & 40 & $0.72 \pm 0.24$ \\
& 6-19 August & 22 & $0.62 \pm 0.14$ \\
33 & 19-25 July & 48 & $1.58 \pm 0.22$ \\
& 26 July-5 August & 40 & $1.56 \pm 0.23$ \\
& 6-19 August & 22 & $1.55 \pm 0.12$ \\
\hline
\end{tabular}

a At these RH values, few umbels had either completely closed or expanded

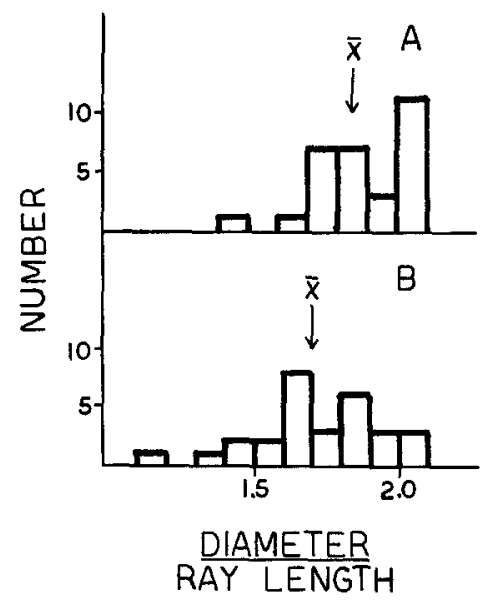

Fig. 6A and B. Distribution of $D / R$ ratios for umbels containing $A$ $<10$ seeds $(N=30)$ and $\mathbf{B}$ Many seeds $(N=29)$. The mean $(\bar{X})$ is indicated for each group

March-collected umbels containing many seeds had a significantly smaller $D / R$ ratio (mean $=1.7, N=29$ ) than did the umbels with less than 10 seeds (mean $=1.86, N=30$ ) (Fig. 6; median stat. $=1.8, p=0.025$ ). In the simulated rain experiment 94 seeds dispersed from the two umbels while open, only 10 while closed. 


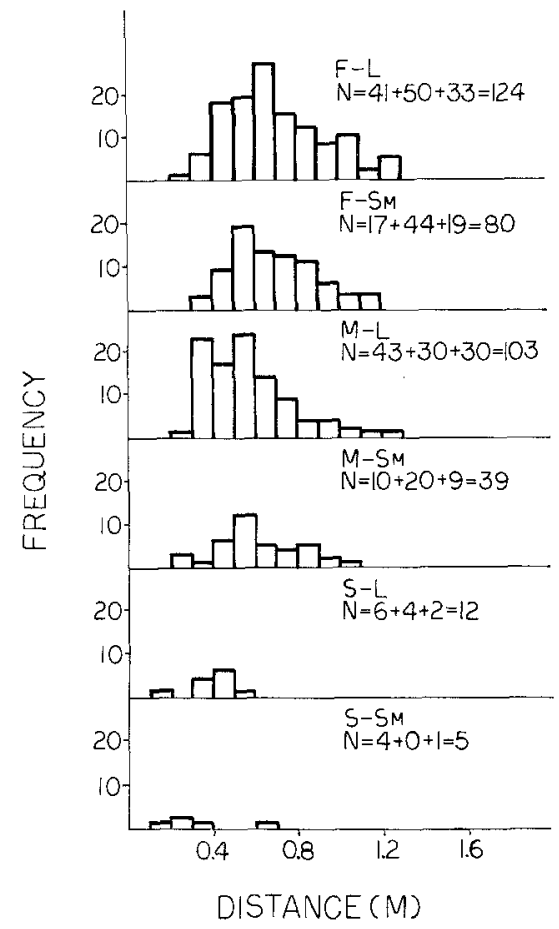

Fig. 7. Seed dispersal distances in fan experiment. Wind speed of fan: $F$, fast ; $M$, medium; $S$, slow; Umbel: $L$, large angle of opening; $S m$, small angle of opening; $N$, total number of seeds dispersed (broken down by replicate)

Table 2. Number of seeds leaving a large- and small-angled umbel at three wind speeds

\begin{tabular}{lll}
\hline Wind speed & Large-angled umbel & Small-angled umbel \\
\hline fast & $124^{\mathrm{a}}$ & 80 \\
medium & 103 & 39 \\
slow & 12 & 5 \\
\hline Total \# seeds & 239 & 124 \\
\hline
\end{tabular}

a This number represents the sum of three replicates

In the fan experiment, regardless of wind speed, fewer seeds always dispersed from the small-angled umbel than from the large-angled umbel (Table 2).

Dispersal distance for seeds from large- versus small-angled umbels at the same wind speed did not differ (Fig. $7 ; X_{\text {fast wind speed }}^{2}$ $\left.=10.44, d f=10, p=0.41 ; X_{\text {medium wind speed }}^{2}=16, d f=10, p=0.10\right)$. However seeds dispersed farther at higher wind speeds ( $X_{\text {fast vs. med. }}^{2}$. $\left.=32.3, d f=10, p<0.001 ; X_{\text {med. vs. slow }}^{2}=30.8, d f=11, p<0.005\right)$.

\section{Discussion}

Hygroscopic movement occurs over a range of relative humidities and increases with time. Consequently it affects both daily and long-term variation in dispersal distance. Data from the fan experiment show that seeds blown from small-angled umbels on the average disperse farther than do those from large-angled umbels. This is because only stronger winds can remove a comparable number of seeds from small-angled umbels (Table 2) and stronger winds carry seeds farther (Fig. 7). Wind will disperse seeds short distances from an umbel when relative humidity is low and longer distances when it is high. The increase in hygroscopic movement with time in concert with the immediate effects of relative humidity ensure both that offspring are dispersed varying distances from the parent and that nearly all offspring eventually disperse. Relative humidity should also affect dispersal by animals because it determines amount of seed exposure to potential dispersal vectors. The importance of varying dispersal distance of offspring is evidenced by experimental studies that show an increase in mortality (Lacey 1978) and a delay in reproduction (Rempel 1974) with increasing density.

Hygroscopic movement also influences dispersal rate; largeangled umbels disperse seeds more quickly than do small-angled umbels. This difference also affects dispersal through space but in this context on a larger scale. The dispersal period for $D$. carota begins in August and extends into winter. Most plants disperse their seeds over several months (Lacey 1978). Of plants beginning dispersal in late August, $30 \%$ contained many seeds in early January. While seeds are usually blown short distances in the fall, my data show that viable seeds are also blown long distances over snow in December and January (Lacey 1978). Hygroscopic movement in many plants ensures that some seeds will be retained until early winter when long distance dispersal is possible. This retention should be particularly important to a species, such as $D$. carota, whose seeds appear to have a short life under natural conditions (Lacey 1978).

The selective forces acting upon hygroscopic movement will ultimately be those arising from the consequences of the resultant spatial and temporal dispersal patterns. Conversely natural selection will act upon dispersal patterns by the survival of those individuals characterized by a certain response to relative humidity. At this point one might ask why there is so much individual variation in hygroscopic movement. The answer lies in the variable consequences of dispersing seeds at different times. I have discussed at length the timing of dispersal elsewhere (Lacey 1978). Briefly, although the most common phenological pattern of seed dispersal is dispersal over several months, there are also plants that disperse seeds quickly (e.g. within one month) and plants that retain seeds so long into the winter that the seeds lose viability. This phenological variation is maintained through environmental fluctuations in 1) quality of the fall versus subsequent summer growing season, which selects for either early and rapid or gradual dispersal, 2) timing of conditions suitable for longer distance dispersal over snow, which selects for time when dispersal should end, and 3) length of time a habitat remains suitable for $D$. carota growth, which selects for proportion of seeds made available for longer distance dispersal in winter. In some years seeds dispersed early are more successful; in other years seeds dispersed late are more successful. The changing consequences of dispersing seeds at different times can maintain a variable dispersal pattern by directly maintaining variability in hygroscopic movement. Although the extent to which hygroscopic movement is under genetic and environment control is unknown, casual observation suggests that hygroscopic movement has a genetic component. I have observed that when a terminal umbel responds little to relative humidity, laterals of the same plant respond similarly. Variation within plants appears to be less than among plants. Current research should elucidate the genetic basis of this response to relative humidity.

Acknowledgments. I thank William Anderson, Janis Antonovics, George Estabrook, Peter Kaufman, Conrad Mason and Daniel Simberloff for constructive comments and help with equipment. This work represents 
a portion of a dissertation submitted to the University of Michigan as partial fulfillment of doctoral degree requirements.

\section{References}

Fitting H, Schenck H, Jost L, Karsten G (1921) Strasburger's Textbook of Botany. McMillan and Co. Ltd London

Guppy HB (1912) Studies in Seeds and Fruits. Williams and Norgate

Haberlandt G (1914) Physiological Plant Anatomy. Montagu Drummond. (Translator from 4th German ed) MacMillan and Co Ltd London

Harper JL (1977) Population Biology of Plants. Academic Press, London

Kerner Anton von Marilaun (1895) The Natural History of Plants. Vol IV Oliver FW (ed), Blackie and Son Ltd London

Lacey EP (1978) The phenology of seed dispersal in Daucus carota L. ssp carota (Apiaceae): An ecological and evolutionary study. Dissertation, University of Michigan Ann Arbor Michigan

Lacey EP (1980) Mode of seed dispersal in Daucus carota L. (Apiaceae) The Michigan Botanist (in press)

Levin DA, Kerster H (1969) Density-dependent gene dispersal in Liatris. American Naturalist 103:61-74
Rempel E (1974) Interference studies on Daucus carota (wild carrot). Master's Thesis University of Guelph Ontario

Ridley HN (1930) The Dispersal of Plants Throughout the World. Wm Clowes and Sons Ltd London

Salisbury EJ (1961) Weeds and Aliens. Collins London

Sheldon JC, Burrows FM (1973) The dispersal effectiveness of the achene-pappus units of selected compositae in wind with convection. New Phytologist 72:665-675

Small E (1978) A numerical taxonomic analysis of the Daucus carota complex. Canadian Journal of Botany 56 (3):248-276

Stebbins GL (1971) Adaptive radiation of reproductive characteristics in angiosperms. II. Seeds and seedlings. Annual Review of Ecology and Systematics 2:237-260

Thellung A (1926) Daucus (in German) by Hegi G (ed), Illustrierte flora von mittel-Europa, Vol V Lehmans JG Munich Germany

Van der Pij1 L (1972) Principles of Dispersal in Higher Plants. Springer Verlag Berlin Heidelberg New York

Wolfenbarger DO (1946) Dispersal of small organisms. American Midland Naturalist 35:1-152

Received December 7, 1979 